\title{
Towards a Standardization of Learning Behavior Indicators in Virtual Environments
}

\author{
Benjamin Maraza-Quispe ${ }^{1}$, Olga Melina Alejandro-Oviedo ${ }^{2}$ \\ Walter Choquehuanca-Quispe ${ }^{3}$, Nicolás Caytuiro-Silva ${ }^{4}$, José Herrera-Quispe ${ }^{5}$ \\ Facultad de Ciencias de la Educación, Universidad Nacional de San Agustín de Arequipa, Arequipa-Perú1, 2, 3 \\ Facultad de Ciencias e Ingenierías Físicas y Formales, Universidad Católica de Santa María, Arequipa-Perú ${ }^{4}$ \\ Facultad de Ingeniería de Producción y Servicios, Universidad Nacional de San Agustín de Arequipa, Arequipa-Perú
}

\begin{abstract}
The need to analyze student interactions in virtual learning environments (VLE) and the improvements this generates is an increasingly emerging reality in order to make timely predictions and optimize student learning. This research aims to implement a proposal of standardized learning behavior indicators in virtual learning environments (VLE) to design and implement efficient and timely learning analytics (LA) processes. The methodology consisted of a data management analysis that was carried out in the Moodle platform of the Faculty of Education Sciences of the National University of San Agustin of Arequipa, with the participation of 20 teachers, where qualitative online questionnaires were used to collect the participants' perceptions. The results propose a standard in terms of indicators of behavior in the teaching-learning process in EVA as they are: Preparation for learning, progress in the progress of the course, resources for learning, interaction in the forums and evaluation of resources. These were evaluated through learning analytics and show the efficiency of the proposed indicators. The conclusions highlight the importance of implementing standardized behavior indicators that allow us to efficiently develop learning analytics processes in VLE in order to obtain better predictions to make timely decisions and optimize the teaching-learning processes.
\end{abstract}

Keywords-Indicators; behavior; learning; analytical; environments; virtual

\section{INTRODUCTION}

Currently most students make use of VLE. We often do not consider the large amount of data left by students as a result of their interactions with these VLE's. Some of its advantages include improving educational decision making by identifying at-risk students and providing timely intervention to help students achieve success, improving instructional course designs, optimizing learning assessments, improving competency determination, and mapping curriculum and recommendations for learning improvement [1].

Currently in the scientific literature we do not find indicators of learning behavior in virtual learning environments that are standardized in order to be used to develop learning analytics. In this context, the following question is asked: To what extent is it possible to standardize learning behavior indicators in virtual learning environments?

According to [2] learning analytics can be defined as the measurement, collection, analysis, and presentation of data about learners and their contexts in order to understand and optimize learning and the environments in which it occurs. [3] learning analytics is the collection, analysis, use, and appropriate dissemination of actionable student-generated data for the purpose of creating appropriate cognitive, administrative, and effective support for students. [4] In other words, learning analytics is a tool that takes a snapshot of a given course by extracting data from the content management system for later analysis. In the same way [2] and [5] highlights LA's major contributions to literature. It includes the latest theories, findings, strategies, tools, and case studies, and focuses on the following uses:

- How to improve the performance of students and teachers.

- How to improve students' understanding of the course material.

- Assessing and Addressing the Needs of Students with Disabilities.

- How to Improve Rating Accuracy.

- How to allow instructors to assess and develop their own strengths.

- How to encourage more efficient use of resources at the institutional level.

The author in [4] highlights that learning analytics provides a centralized space for information across semesters, sections, instructors, students, and assignments. In this sense, the learning analysis process is unique in that it links large amounts of student-generated data to produce metrics or visualizations that can be used to improve the educational experience [6]. In accordance with [7] One of the main technologies used for the management of distance learning courses is the Learning Management System (LMS). Many higher education institutions have adopted the LMS; however, the negative perception of the LMS by faculty diminishes its potential for a system-wide approach to implementing a learning analysis strategy.

However, more recent research in the area of learning analytics, attempts to understand the reactions of students and learners when visualizing data and presenting it in the dashboard. For example, [8] consider that students and teachers are not able to interpret the information provided by the most common dashboards and, therefore, the effects on their 
learning are non-existent and sometimes even negative. Therefore, as some researchers point out [9], [10], it is necessary to focus more on how to understand the meaning of the data provided by the dashboards, so that there is a positive influence on the student's own learning scenario. However, research on the pedagogical use of data visualization and its impact on the student's learning process is scarce. And this is precisely the aim of this research: To propose standards in terms of indicators of learning behavior to be analyzed in VLE in order to develop better predictions to optimize the teachinglearning processes.

\section{STATE OF THE ART}

\section{A. Learning Analytics Models}

Using a general morphological analysis methodology, analyze the discussions in the learning analytics communities; through this method they raise a model, which focuses on its fundamental structure [11]. This model has six dimensions: Actors, objectives, data, instruments, external constraints and internal limitations. From this model it can be highlighted that the fundamental objectives of learning analytics are reflection and prediction.

Another aspect that is worth highlighting, and that is related to its link with other related fields, is that the instruments dimension of learning analytics, is oriented to the conversion of the Big Data from its original state (that is, unstructured, complex, etc.), into useful information. Under this premise, learning analytics is nourished by analytical instruments from various fields, such as Machine Learning or classic statistical analysis.

A common factor, among the models presented by [12], [13], [14], is that they delimit the life cycle of the learning analytics process, from a common starting point, such as data collection, to a final stage that varies according to the model. Table I presents the stages that have been followed to make the example of sample analysis of the data obtained considering our proposal.

The model proposed by [14] has a systemic approach where, in addition to the analytical process, support resources are systematized. From this model it is highlighted that information collection is subject to the purpose of analysis, which can incorporate purely research, academic, institutional, management, etc. motivations. As for the analysis, the techniques and tools are varied and include social network analysis, neurolinguistic programming, prediction, risk assessment, support search or concept development, among others.

TABLE I. StAGES OF THE LEARNING ANALYTICS CyCLE [14]

\begin{tabular}{|l|l|}
\hline Model & Stages of the Learning Analytics Cycle \\
\hline & 1. Data collection and acquisition \\
& 2. Storage \\
3iemens & 4. Data Cleaning \\
$(2013)$ & 5. Analysis \\
& 6. Representation and visualization \\
& 7. Action (intervention, optimization, alerts, etc.) \\
& 8. Restarting the process (loop) \\
\hline
\end{tabular}

\section{METHOD}

The methodology used presents a quantitative approach because we use data collection and analysis to answer research questions and test a previously established hypothesis and rely on numerical measurement, counting, and statistics are used to accurately establish indicators of learning behavior in virtual learning environments.

\section{A. Objective}

To propose standardized learning behavior indicators in Virtual Learning Environments in order to design and implement learning analytics processes to develop timely predictions and optimize learning.

\section{B. Context and Sample}

The research was conducted using the Moodle platform of the National University of San Agustín de Arequipa: https:/aulavirtual.unsa.edu.pe/aulavirtual/ in the Faculty of Educational Sciences, where the courses are currently taught in the online mode. However, taking into account that the indicators of learning behavior to be observed should be standardized in order to carry out more precise analyses regarding the teaching-learning processes in the online modality, the research was developed with 20 teachers of this modality. The selection criteria were carried out through a simple random sampling of a total population of 70 teachers.

\section{Procedure}

Online questionnaires were used for the collection of qualitative data which were answered by the 20 teachers of the Faculty. Based on the observation of the data obtained through the IntelliBoard module and the survey developed, the indicators of learning behavior in EVA were standardized.

To validate the proposal, data collection was carried out through the IntelliBoard module installed in the university's Moodle platform and an analysis of this data was made considering the learning behavior indicators developed in our proposal.

\section{Data Collection Instrument}

The open-ended questionnaire was designed following the framework proposed by [15] and aims to understand teachers' perceptions of the most appropriate learning behavior indicators to be standardized. The questionnaire consists of 10 questions. The data obtained were analyzed according to previously stated analysis criteria. Also, data collection was done through the IntelliBoard module that was installed in the Moodle platform. IntelliBoard offers analytical and reporting services for education communities and institutions using the Moodle platform. IntelliBoard extracts static data collected in Moodle and presents consistent data in graph and report formats. With the power to convert this analytical data into simple, easy-to-read reports, IntelliBoard.net becomes the primary reporting tool [16].

\section{ANAlysis AND RESUlts}

\section{A. Selection of Learning behavior Indicators in EVA}

According to the results obtained, the indicators of learning behavior directly affect the accuracy and credibility of the 
prediction of student performance. Therefore, scientifically selecting effective learning behavior indicators is an important part of predicting student performance [17]. Because of the diversity of online learning behaviors, and the complexity of the correlation between behaviors, not all indicators of learning behavior can affect learning and data can be collected in a quantitative way. Therefore, based on existing research results, combining the characteristics of the online course, were classified into five stages: Preparation of learning, progress of the curriculum, resources for learning, interaction in the forums and evaluation of activities, in different dimensions and content, through them are obtained the indicators of learning behaviors related to online learning activities on the platform. Sixteen learning behavior indicators were selected for the study as shown in Table II.

In Table II, the review of resources is calculated by the total time of the learning resources (recommended time) divided by the time the student spends on the learning resources, reflecting the completion of learning. The amount of resource review refers to the number of resource review time divided by the difference in time between the last resource view and the first view, reflecting the students' concentration. The number of submissions is calculated by the number of test submissions divided by the difference in time between the last submission and the first submission.

\section{B. Standardization of Learning behavior Indicators in Virtual Environments}

Table III shows the standardization of the learning behavior indicators implemented from the data provided by the 20 teachers in 20 different courses.

Achievement levels are categories that classify students according to their performance where belonging to each of these levels of achievement describes the knowledge and skills developed by students. These achievement levels were implemented based on the International Standard Classification of Education according to UNESCO [19].

TABLE II. INDICATORS OF E-LEARNING BEHAVIOR OBSERVED

\begin{tabular}{|c|c|c|c|}
\hline Learning process & Dimension & Content & Indicator \\
\hline \multirow{2}{*}{ Preparation } & \multirow{2}{*}{ Before class } & Before class & Number of views of the course presentation \\
\hline & & Assistance & Number of accesses to the course \\
\hline \multirow{2}{*}{$\begin{array}{l}\text { Curriculum } \\
\text { progress }\end{array}$} & \multirow{2}{*}{ Learning Objectives } & \multirow{2}{*}{ Related to } & Number of revised course pages \\
\hline & & & Time to review resources \\
\hline \multirow{5}{*}{ Learning Resources } & \multirow{2}{*}{ Gathering information } & \multirow{2}{*}{ Importance of learning resources } & Completion of resource review \\
\hline & & & Number of resources reviewed \\
\hline & \multirow{2}{*}{ Information processing } & \multirow{2}{*}{$\begin{array}{l}\text { Persistence in reviewing } \\
\text { resources }\end{array}$} & Number of resources reviewed repeatedly \\
\hline & & & Number of resources reviewed after completion of course \\
\hline & $\begin{array}{l}\text { Collection and processing of } \\
\text { information }\end{array}$ & Other learning resources & Access number to other resources \\
\hline \multirow{3}{*}{$\begin{array}{l}\text { Interaction in the } \\
\text { forums }\end{array}$} & \multirow{3}{*}{ Information about the publication } & \multirow{3}{*}{ Interactive participation } & Number of searches in the forum \\
\hline & & & Number of publications in the forum \\
\hline & & & Number of responses in the forum \\
\hline \multirow{4}{*}{$\begin{array}{l}\text { Evaluation of } \\
\text { activities }\end{array}$} & \multirow{4}{*}{ Information used } & \multirow{2}{*}{$\begin{array}{l}\text { Amount of information } \\
\text { completed }\end{array}$} & Number of published activities \\
\hline & & & Average of activities developed \\
\hline & & \multirow[t]{2}{*}{ Successful completion } & $\begin{array}{l}\text { time difference between the uploaded resource and the start of } \\
\text { the activity }\end{array}$ \\
\hline & & & Quantity of the shipment \\
\hline
\end{tabular}

TABLE III. INDICATORS STANDARDIZATION OF LEARNING BEHAVIOR INDICATORS IN VIRTUAL ENVIRONMENTS

\begin{tabular}{|c|c|c|c|}
\hline Dimension & Learning behavior indicators & Achievement levels & Standardization of levels in \% \\
\hline \multirow{8}{*}{ Before class } & \multirow{4}{*}{ Number of views to the course presentation } & In start & $0 \%-20 \%$ \\
\hline & & In process & $21 \%-50 \%$ \\
\hline & & Satisfactory & $51 \%-80 \%$ \\
\hline & & Excellent & $81 \%-100 \%$ \\
\hline & \multirow{4}{*}{ Number of accesses to the course } & In start & $0 \%-30 \%$ \\
\hline & & In process & $31 \%-60 \%$ \\
\hline & & Satisfactory & $61 \%-80 \%$ \\
\hline & & Excellent & $81 \%-100 \%$ \\
\hline \multirow{3}{*}{ Learning objectives } & \multirow{3}{*}{ Number of revised course pages } & In start & $0 \%-20 \%$ \\
\hline & & In process & $21 \%-50 \%$ \\
\hline & & Satisfactory & $51 \%-80 \%$ \\
\hline
\end{tabular}




\begin{tabular}{|c|c|c|c|}
\hline & & Excellent & $81 \%-100 \%$ \\
\hline \multirow{8}{*}{ Information gathering } & \multirow{4}{*}{ Completion of resource review } & In start & $0 \%-30 \%$ \\
\hline & & In process & $31 \%-60 \%$ \\
\hline & & Satisfactory & $61 \%-80 \%$ \\
\hline & & Excellent & $81 \%-100 \%$ \\
\hline & \multirow{4}{*}{ Amount of resources reviewed } & In start & $0 \%-30 \%$ \\
\hline & & In process & $31 \%-60 \%$ \\
\hline & & Satisfactory & $61 \%-80 \%$ \\
\hline & & Excellent & $81 \%-100 \%$ \\
\hline \multirow{8}{*}{ Information processing } & \multirow{4}{*}{ Number of resources reviewed repeatedly } & In start & $0 \%-20 \%$ \\
\hline & & In process & $21 \%-50 \%$ \\
\hline & & Satisfactory & $51 \%-80 \%$ \\
\hline & & Excellent & $81 \%-100 \%$ \\
\hline & \multirow{4}{*}{$\begin{array}{l}\text { Number of resources reviewed after } \\
\text { finishing the course }\end{array}$} & In start & $0 \%-20 \%$ \\
\hline & & In process & $21 \%-50 \%$ \\
\hline & & Satisfactory & $51 \%-80 \%$ \\
\hline & & Excellent & $81 \%-100 \%$ \\
\hline \multirow{4}{*}{$\begin{array}{l}\text { Information collection and } \\
\text { processing }\end{array}$} & \multirow{4}{*}{ Access number to other resources } & In start & $0 \%-30 \%$ \\
\hline & & In process & $31 \%-60 \%$ \\
\hline & & Satisfactory & $61 \%-100 \%$ \\
\hline & & Excellent & $81 \%-100 \%$ \\
\hline \multirow{12}{*}{ Publication information } & \multirow{4}{*}{ Number of searches in the forum } & In start & $0 \%-20 \%$ \\
\hline & & In process & $21 \%-50 \%$ \\
\hline & & Satisfactory & $51 \%-80 \%$ \\
\hline & & Excellent & $81 \%-100 \%$ \\
\hline & \multirow{4}{*}{ Number of forum posts } & In start & $0 \%-20 \%$ \\
\hline & & In process & $21 \%-50 \%$ \\
\hline & & Satisfactory & $51 \%-80 \%$ \\
\hline & & Excellent & $81 \%-100 \%$ \\
\hline & \multirow{4}{*}{ Number of responses in the forum } & In start & $0 \%-20 \%$ \\
\hline & & In process & $21 \%-50 \%$ \\
\hline & & Satisfactory & $51 \%-80 \%$ \\
\hline & & Excellent & $81 \%-100 \%$ \\
\hline \multirow{16}{*}{ Information used } & \multirow{4}{*}{ Number of published activities } & In start & $0 \%-20 \%$ \\
\hline & & In process & $21 \%-50 \%$ \\
\hline & & Satisfactory & $51 \%-80 \%$ \\
\hline & & Excellent & $81 \%-100 \%$ \\
\hline & \multirow{4}{*}{ Average of activities carried out } & In start & $0 \%-30 \%$ \\
\hline & & In process & $31 \%-60 \%$ \\
\hline & & Satisfactory & $61 \%-80 \%$ \\
\hline & & Excellent & $81 \%-100 \%$ \\
\hline & \multirow{4}{*}{$\begin{array}{l}\text { time difference between the uploaded } \\
\text { resource and the start of the activity }\end{array}$} & In start & $0 \%-20 \%$ \\
\hline & & In process & $21 \%-50 \%$ \\
\hline & & Satisfactory & $51 \%-80 \%$ \\
\hline & & Excellent & $81 \%-100 \%$ \\
\hline & \multirow{4}{*}{ Number of shipments } & In start & $0 \%-20 \%$ \\
\hline & & In process & $21 \%-60 \%$ \\
\hline & & Satisfactory & $61 \%-80 \%$ \\
\hline & & Excellent & $81 \%-100 \%$ \\
\hline
\end{tabular}




\section{VALIDATION OF THE PROPOSAL}

In order to validate the proposal in terms of indicators of learning behavior, an analysis of data obtained through the technique of linear regression, which is a supervised learning algorithm used in Machine Learning and statistics. In its simplest version, what we will do is "draw a line" that will indicate the trend of a set of continuous data. In statistics, linear regression is an approach to model the relationship between an independent scalar variable "X", and one or more independent explanatory variables "Y".

In Fig. 1, taking into account the indicator of learning behavior: Number of visits to the presentation or introduction of the course, we have that the highest number of visits to the introduction of the course is concentrated in an average of 10 students and the lowest number of visits is concentrated between 30 to 40 students, which will allow making timely decisions in order to improve the number of visits to the presentation of the course.

In Fig. 2, taking into account the indicator of learning behavior: Number of pages reviewed in the course, we have an average of 2.5 out of a total of 100 students have reviewed all the pages of the course, which will allow making timely decisions in order to improve the number of pages reviewed in the course.

In Fig. 3, taking into account the learning behavior indicator: Number of assignments sent, an average of 18 students has sent the highest number of assignments, while an average of 6 students has not sent any assignment, which will allow making timely decisions in order to improve the number of assignments sent.

In Fig. 4, taking into account the learning behavior indicator: Number of accesses to the course, 15 students have made their access an average of 75 times to the course and 5 students have made their access an average of 174 times, which represents a minimum amount, which will allow us to make timely decisions in order to improve the number of accesses to the course.

In Fig. 5, taking into account the learning behavior indicator: Time spent reviewing resources, a minimum average of students dedicates 12.5 hours to the review of resources, while a higher average of students dedicates a lower average of time to the review of resources; which will allow us to make timely decisions in order to improve the time each student dedicates to the development of the course.

In Fig. 6, taking into account the learning behavior indicator: Number of posts in the forum, we have that an average of 37 students make a greater number of posts, while an average of 6 students do not make posts; this will allow us to make timely decisions in order to improve the number of posts in the forum.

According to the proposed behavior indicators, the graphs show which values are concentrated among most records to be analyzed. Regarding behaviors, students interact with the elements of the learning context: Forums, resources, submissions. In the interaction of the digital elements the students generate traces. These traces identify the behavior of each student only and only in these digital elements. Somehow, this behavior forms patterns. The student adopts these patterns as a solution to learning situations. So, analyzing these patterns allows the extraction of learning indicators. One of the objectives of learning behavior indicators in VLE is to break or alter learning behavior patterns so that the student adopts healthier ones. The indicators help the teacher to know the learning patterns that the students adopt. At the same time, it allows to check which students leave the standard, do different actions and how, for example, to approach the tutorial actions. Establishing indicators offers a learning opportunity for both the student and the teacher. The teacher must be aware that behavior $\mathrm{X}$ is not the cause of effect Y. However, there may be a correlation. Discovering patterns of behavior helps the teacher to alert the student, test new behaviors, and check results [1].

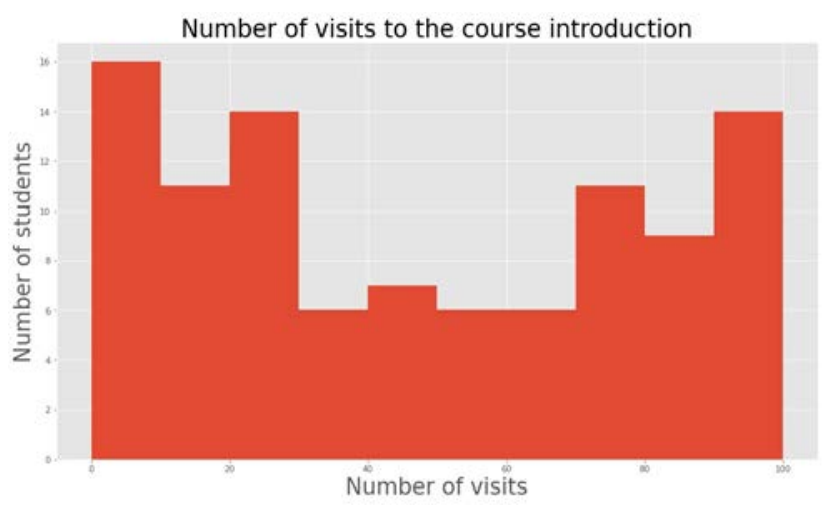

Fig. 1. Number of Visits to the Course Introduction.

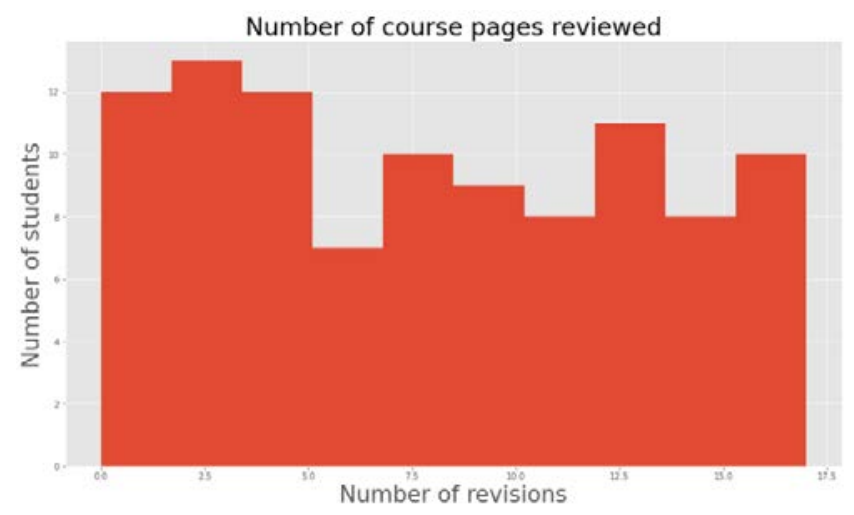

Fig. 2. Number of Pages Reviewed in the Course.

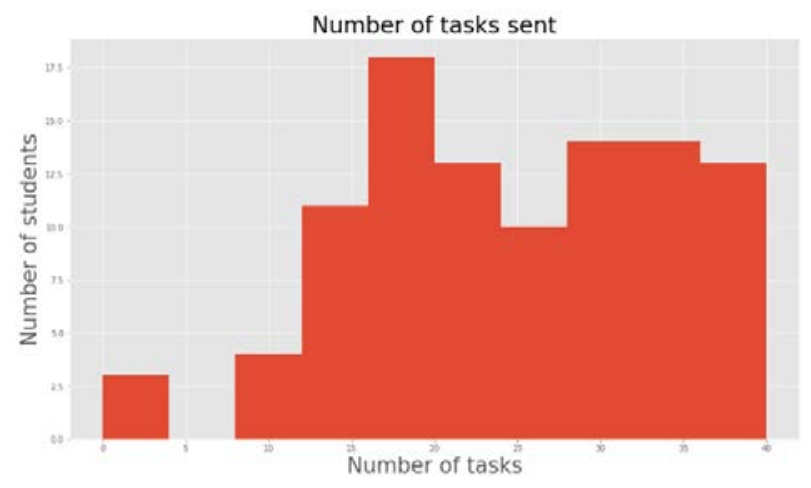

Fig. 3. Number of Assignments Sent. 


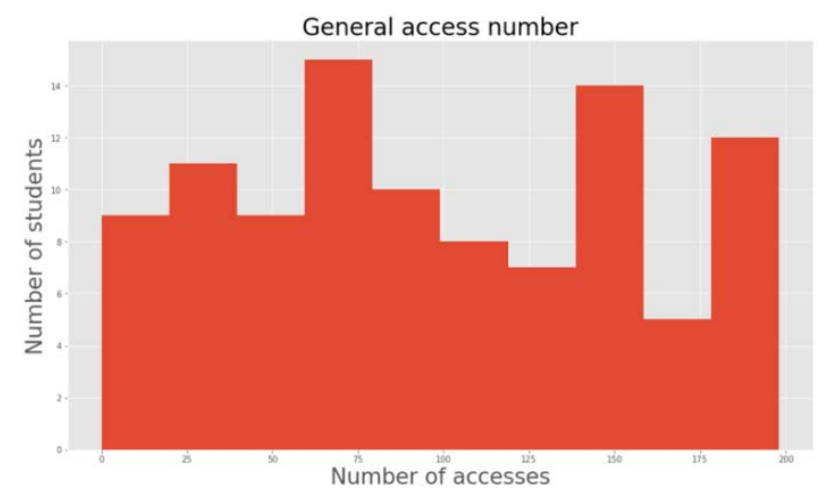

Fig. 4. Number of Accesses to the Course.

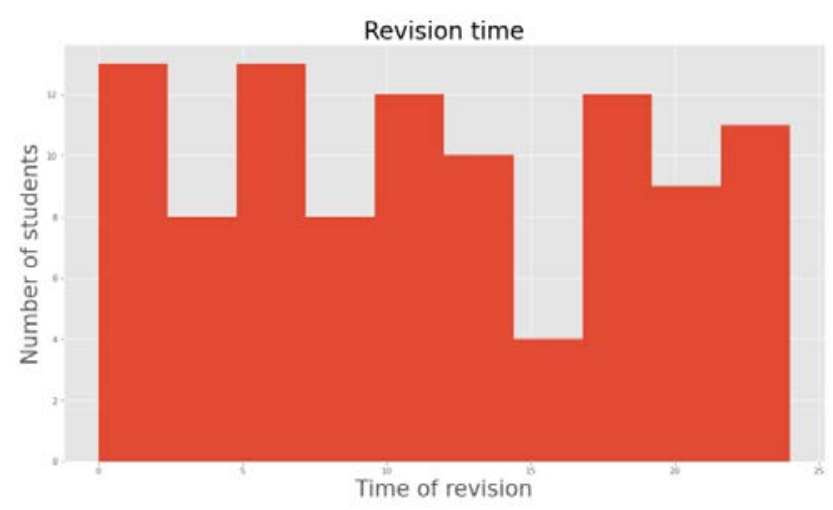

Fig. 5. Time Spent Reviewing Resources.

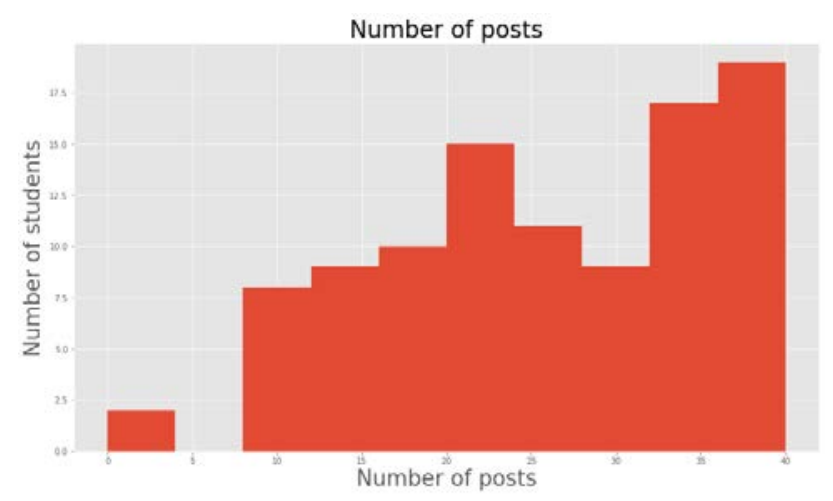

Fig. 6. Number of Posts in the Forum.

Table IV shows the data obtained by considering these standardized indicators where behaviors can be aggregated into patterns. The patterns can be aggregated into indicators. Indicators can be aggregated into predictions. Predictions will allow us to make timely decisions, [18]. A prediction result is a summary of interactions, patterns and behaviors. A prediction facilitates a reflection that allows us to follow, guide and tutor the student in his learning process.

In Fig. 7, we can see an example of Prediction in simple linear regression developed with the data obtained taking into account the standardized learning behavior indicators, which show us that if we take into account these indicators, reliable predictions can be made to make timely decisions regarding the improvement of the teaching-learning processes in virtual learning environments. [20].
TABLE IV. SUMMARY OF DATA OBTAINED CONSIDERING THE PROPOSED BEHAVIORAL INDICATORS

\begin{tabular}{|l|l|l|}
\hline & $\begin{array}{l}\text { Number of Resources } \\
\text { reviewed }\end{array}$ & $\begin{array}{l}\text { Number of posts in the } \\
\text { Forum }\end{array}$ \\
\hline Count & 100.000000 & 100.000000 \\
\hline Mean & 23.310000 & 23.640000 \\
\hline Std & 9.465189 & 9.478865 \\
\hline Min & 5.000000 & 3.000000 \\
\hline $25 \%$ & 15.000000 & 15.000000 \\
\hline $50 \%$ & 22.500000 & 23.000000 \\
\hline $75 \%$ & 32.000000 & 32.000000 \\
\hline Max & 42.000000 & 40.000000 \\
\hline
\end{tabular}

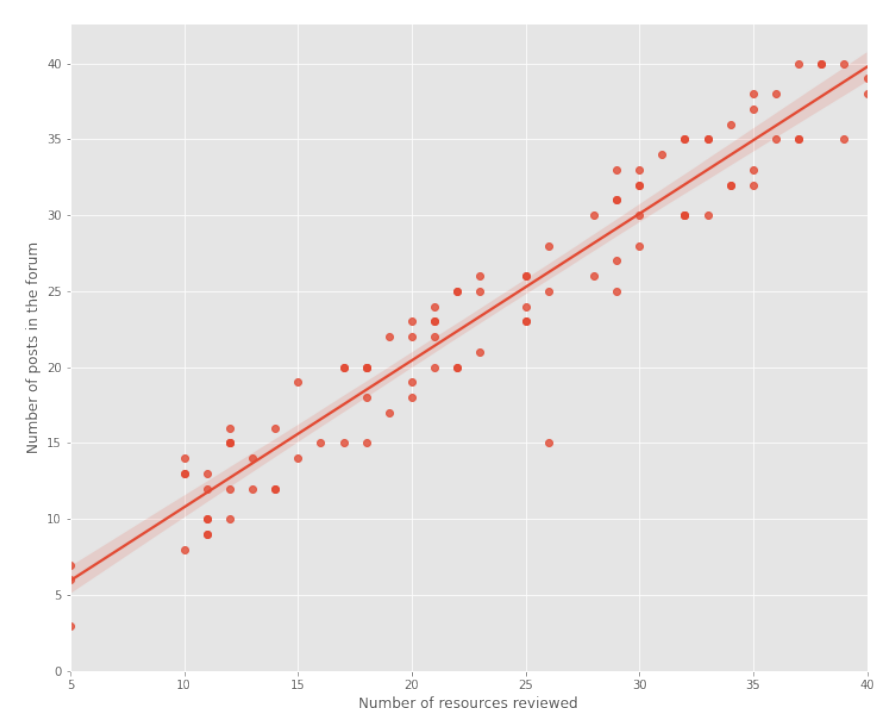

Fig. 7. Example of Data Analysis using the Linear Regression Technique using the Proposed Indicators.

\section{DISCUSSION}

Although it is true that in the reviewed literature there is no information regarding the standardization of learning behavior indicators in virtual learning environments, it has been possible to standardize 16 online learning behavior indicators according to achievement levels: Initially, in process and satisfactory. $100 \%$ of the teachers surveyed express their agreement with these indicators, which can be applied to different contexts according to needs.

The results obtained through data management in the Moodle platform with the IntelliBoard module and the survey developed to teachers prioritize the importance of visualizing standardized educational data in order to develop learning analytics with more accurate predictions to optimize the teaching-learning process of students in a meaningful way.

\section{CONCLUSIONS}

These indicators of learning behaviors in VLE are very important for self-regulation and reflection of students and teachers within their teaching and learning context. Likewise, teachers could provide very effective feedback by knowing the indicators of learning behavior in which they have weaknesses. That is why teachers considered that these data could help in the redesign of their courses. 
After a validation process, it is concluded that there are 16 indicators that are prioritized for an effective analysis of the data using learning analytics techniques, which would allow the implementation of better predictions in order to make timely decisions to optimize the teaching-learning processes in virtual learning environments.

Learning Analytics (LA) has attracted a great deal of attention. In recent years as educational institutions and researchers are increasingly seeing the potential that LA has to support the learning process. LA approaches share a movement from data to analysis to action to learning. LA is an interdisciplinary field in which several related research areas converge.

In the future it is recommended to collect data from a larger sample of teachers, also collect qualitative data from students and then compare them between the two roles. In addition, it is required to perform more in-depth analysis tests using learning analytics techniques combined with Artificial Intelligence.

\section{REFERENCES}

[1] Maraza, B. (2016). Towards Personalized Learning in Virtual Environments. Virtual Campuses, 5(1), 20-29. From http://www. uajournals.com/ojs/index.php/campusvirtuales/article/viewFile/111/100.

[2] Calvet, L., \& Juan, Á. (2015). Educational Data Mining and Learning Analytics: differences, similarities, and time evolution. Revista de Universidad y Sociedad del Conocimiento, 98-112.

[3] Slade, S., \& Prinsloo, P. (2013). Learning analytics: Ethical issues and dilemmas. American Behavioral Scientist, 57, 1510-1529.

[4] Lindsey, B. (2016). Incorporating Learning Analytics into Basic Course Administration: How to Embrace the Opportunity to Identify Inconsistencies and Inform Responses. Journal of the Association for Communication Administration, 2-13.

[5] Larusson, J., \& White, B. (. (2014). Learning Analytics: from Research to Practice. New York: Springer Science+Business Media.

[6] Clow, D. (2012). The learning analytics cycle: Closing the loop effectively. Proceedings of the 2nd International Conference on Learning Analytics and Knowledge, 134-138. J. A.

[7] Bollenback, D., \& Glassman, A. (2018). Big data in higher education: Adjunct faculty perceptions of learning analytics and their uses. Issues in Information Systems, 71-80.
[8] Corrin, L., \& de Barba, P. (2015). How do students interpret feedback delivered via dashboard? Paper presented at the International Conference on Learning Analytics and Knowledge, Poughkeepsie, NY.

[9] Dawson, S., Gasevic, D., Siemens, G., \& Joksimovic, S. (2014). Current state and future trends: a citation network analysis of the learning analytics field. Paper presented at the International Conference on Learning Analytics and Knowledge, Indianapolis, IN.

[10] Wise, A. F. (2014). Designing pedagogical interventions to support student use of learning analytics. Paper presented at the International Conference on Learning Analytics and Knowledge, New York, NY.

[11] Greller, W. y Drachsler, H. (2012). Translating Learning into Numbers: A Generic Framework for Learning Analytics. Educational Technology \& Society, 15(3), 42-57.

[12] Martin, T. y Sherin, B. (2013). Learning Analytics and Computational Techniques for Detecting and Evaluating Patterns in Learning: An Introduction to the Special Issue. Journal of the Learning Sciences, 22(4), 511-520. doi: 10.1080/10508406.2013.840466.

[13] Picciano, A. (2012). The Evolution of Big Data and Learning Analytics in American Higher Education. Journal of Asynchronous Learning Networks, 16(3), 9-20.

[14] Siemens, G. (2013). Learning Analytics: The Emergence of a Discipline. American Behavioral Scientist, 57(10), 1380-1400. doi: 10.1177/0002 764213498851.

[15] Pardo, A., Jovanovic, J., Dawson, S., Gasevic, D., \& Mirriahi, N. (2017). Using learning analytics to scale the provision of personalised feedback. British Journal of Educational Technology. https://doi.org/ 10.1111/bjet.12592.

[16] Intelliboard. (2019). Intelliboard. Retrieved October 20, 2019, from https://intelliboard.net/about.

[17] Villagrá-Arnedo C J, Gallego-Durán F J, Llorens-Largo F. 2016. Improving the expressiveness of black-box models for predicting student performance[J]. Computers in Human Behavior, 72.

[18] Maraza-Quispe, B., Alejandro-Oviedo, O., Fernández-Gambarini, W., Cisneros-Chavez, B., \& Choquehuanca-Quispe, W. (2020). Analysis of YouTube as a documentary research tool in higher education students. Publications, 50(2), 133-147. doi:10.30827/publicaciones.v50i2.13949.

[19] Instituto de Estadística de la Unesco. 2011. Clasificación Internacional Normalizada de Educación. CINE 2011. From https://unesdoc. unesco.org/ark:/48223/pf0000220782.

[20] Maraza-Quispe, B., Alejandro-Oviedo, O., Choquehuanca-Quispe, W., Hurtado-Mazeyra, A., Fernandez-Gambarini, W. (2019). e-Learning Proposal Supported by Reasoning based on Instances of Learning Objects. International Journal of Advanced Computer Science and Applications, Vol. 10, No. 10. From https://thesai.org/Downloads/ Volume10No10/Paper_35-E_Learning_Proposal_Supported_by_ Reasoning.pdf. 